GLOBAL WATER PATHOGEN PROJECT

PART THREE. SPECIFIC EXCRETED PATHOGENS: ENVIRONMENTAL AND EPIDEMIOLOGY ASPECTS

\title{
TAENIA SPP.
}

\section{Armando Gonzalez}

Johns Hopkins Bloomburg School of Public Health

Baltimore, United States

\section{Lian Thomas}

International Livestock Research Institute

Institute for Infection \& Global Health, University of Liverpool

Nairobi, Kenya 


\section{Copyright:}

\section{cc) (1) (2) \\ BY SA}

This publication is available in Open Access under the Attribution-ShareAlike 3.0 IGO (CC-BY-SA 3.0 IGO) license (http://creativecommons.org/licenses/by-sa/3.0/igo). By using the content of this publication, the users accept to be bound by the terms of use of the UNESCO Open Access Repository (http://www.unesco.org/openaccess/terms-use-ccbysa-en).

\section{Disclaimer:}

The designations employed and the presentation of material throughout this publication do not imply the expression of any opinion whatsoever on the part of UNESCO concerning the legal status of any country, territory, city or area or of its authorities, or concerning the delimitation of its frontiers or boundaries. The ideas and opinions expressed in this publication are those of the authors; they are not necessarily those of UNESCO and do not commit the Organization.

\section{Citation:}

Gonzalez, A. and Thomas, L. (2018). Taenia spp. In: J.B. Rose and B. Jiménez-Cisneros (eds), Water and Sanitation for the 21st Century: Health and Microbiological Aspects of Excreta and Wastewater Management (Global Water Pathogen Project). (L. Robertson (eds), Part 3: Specific Excreted Pathogens: Environmental and Epidemiology Aspects - Section 4: Helminths), Michigan State University, E. Lansing, MI, UNESCO. https://doi.org/10.14321/waterpathogens.40

Acknowledgements: K.R.L. Young, Project Design editor; Website Design: Agroknow (http://www.agroknow.com)

Last published: April 12, 2018 


\section{Summary}

Tapeworms of the genus Taenia include over 100 species. Members of the genus are characterised by a ribbon-like appearance comprised of multiple, eggcontaining segments called 'proglottids'. Taenia spp. lifecycle relies on a vertebrate intermediate host in which the infective larvae (cysticerci) develop and a definitive host which ingests the uncooked flesh of the intermediate host containing the cysticerci which develops in the smallintestine into the adult tapeworm. The tapeworm proglottids are released from the definitive host and intermediate hosts are infected by ingesting the tapeworm eggs from the proglottids. Taenia spp. eggs have been demonstrated to survive for periods of months or years on pasture, with low to moderate temperatures and high humidity being associated with long survival times.

Humans are the definitive host for three Taenia species ( $T$. saginata, T. solium, T. asiatica). The accidental ingestion of T. solium eggs by humans, through poor hand hygiene, contaminated water or faecal contamination of food, can result in the aberrant larval infection human cysticercosis. Neurocysticercosis, infection of the nervous system, is one of the most common causes of preventable epilepsy in endemic countries and has been estimated to be responsible for a loss of 503,000 (379,000-663,000) DALYs yearly.

Human taeniosis infections (with the adult tapeworm) have generally rather mild clinical effects and are susceptible to praziquantel, niclosamide or triple dose albendazole. Neurocysticercosis, however, requires careful surgical or medical management due to the sensitive location of the larval cysts and potential critical complications that can occur.

As well as anthelmintic treatment of the definitive or intermediate hosts, the control of Taenia spp. relies on stringent meat inspection, education on safe meat preparation, personal hygiene and, importantly, the careful management of potentially contaminated domestic effluent and sewage sludge.

The zoonotic tapeworms Taenia saginata and Taenia solium, are known as the beef tapeworm and pork tapeworm, respectively, depending on their intermediate host. A third species, Taenia asiatica, the Asian tapeworm, although genetically closest to $T$. saginata, also utilises a porcine intermediate host (Flisser, 2006). In the definitive, human, host infections with the adult stage of Taenia spp. (taeniosis) have only mild health implications through gastro-intestinal disturbance. The larval stage of T. solium, can however infect humans as aberrant intermediate hosts, an infection known as cysticercosis. This can result in severe disease including epileptic seizures due to cyst development in the brain (neurocysticercosis). Humans acquire cysticercosis through ingestion of $T$. solium eggs for instance in excreta or through contaminated water and food-stuffs. Correct treatment and handling of excreta, raw sewerage and sewerage sludge is therefore of incredible importance for the safety of both sanitation workers and the public.

\subsection{Epidemiology of Taenia Saginata and Taenia Solium}

The zoonotic tapeworms Taenia saginata and solium like their definitive host (humans) have a global distribution and wid ecological niche, T. saginata being recorded on every continent with the exception of Antarctica and $T$. solium being recorded in the majority of countries where pork is consumed. Regions reporting T. solium infections in the porcine or human hosts include Africa (Braae et al., 2015) and Asia (Rajshekhar et al., 2003), Latin America (Coral-Almeida et al,. 2015), North America (Cantey et al., 2014; DeGiorgio et al., 2005) and Europe (Devleesschauwer et al., 2015).

Key risk factors for Taenia spp. infection in both intermediate and definitive hosts includes poor sanitary conditions, contaminated water, outdoor and free-range animal husbandry, poor meat inspection and lack of health education. These risk factors are highly prevalent in less developed countries and are reflected in the high prevalence of Taenia spp. found in these countries. While it is generally thought that improved pig husbandry and sanitary conditions in Europe have effectively eradicated $T$. solium, a recent review suggests that this may not be entirely true (Devleesschauweret al., 2015). Valid epidemiological data are still lacking for both parasites on a country-by-country basis, and prevalence levels are difficult to compare due to the differing diagnostic methodologies utilised in many studies.

\subsection{Global Burden of Disease}

The 2010 Global Burden of Disease (GBD) survey estimated that human cysticercosis (caused by T. solium) was responsible for 503,000 (95\% C.I. 379,000-663,000) DALYs lost annually (Murray et al., 2012). It is felt by many, however that this under-estimates the true burden. It is also estimated that approximately $30 \%$ of epilepsy in endemic areas is attributable to neurocysticercosis (NCC) (Rajshekhar et al., 2006, Ndimubanzi et al., 2010, Bruno et al., 2013) and extrapolating from the DALYs attributable to epilepsy from the 2010 GDB survey it is likely that the DALYs attributable to $T$. solium should be in the region of 2.7million (95\% C.I. 2.16-3.61 million) (Torgerson et al., 2015). T. solium is also thought to be responsible for approximately 28 thousand deaths worldwide on an annual basis (95\% C.I. 21-37,000) (Torgerson et al., 2015).

\subsubsection{Symptomatology}

Intestinal taeniosis is generally asymptomatic (Garcia et al., 2003), although mild abdominal discomfort has been reported (Tembo and Craig 2015). Rare reported sequale to intestinal taeniosis include Cholangitis (an infection of the biliary tract) (Uygur-Bayramicli et al., 2012), gall bladder perforation (Hakeem et al., 2012), appendicitis (Kulkarni et al., 2014) and bowel obstruction (Atef and Emna, 2015; Li et al., 2015). Some people suffering from taeniosis will notice the passage of proglottids (parasite segments containing eggs) in their faeces, although this seems most common with the more motile proglottids of $T$. saginata 
(Garcia et al., 2003).The major health burden imposed by $T$. solium is human cysticercosis caused by the ingestion of eggs, or via auto-infection within individuals with taeniosis, and the subsequent aberrant encystment of the larval stage within humans. T. solium larvae can encyst in various places throughout the human body, although muscular, subcutaneous, ocular and neuro-cysticercosis are the most common presentations (Gonzales et al., 2016). The most common form of human cysticercosis infection, and that causing the majority of associated morbidity, is the presence of a cyst or cysts within the central nervous system (CNS) termed neurocysticercosis (NCC). Larvae invade the CNS and establish a viable cysticerci within the brain parenchyma or in the extra-parenchymal space (Gonzales et al., 2016).

\subsubsection{Economic Impact}

T. saginata is the most common cause of taeniosis in humans, with an estimated 60 to 70,000 carriers worldwide (Flisser et al., 2011). In comparison to the large public health burden of T. solium, however, T. saginata is an infection primarily of economic importance through the condemnation, downgrading and processing of carcasses and organs containing cysts (Boone et al., 2007; Torgerson, 2013). Regulations such as EU regulation 854/2004 and the Kenyan Meat Control Act (CAP 356) requires that generalised infections of cattle with cysticercosis requires that the meat is declared unfit for human consumption or, in the case of localised infections the carcass, or uninfected parts of the carcass are declared fit for consumption only after cold treatment $\left(-10^{\circ} \mathrm{C}\right.$ for10days -3 weeks) (Abuseir et al., 2006; Government of Kenya, 2012). The extra handling, condemnation, the weight loss (2 to $5 \%$ ) and reduced value of meat after freezing, potentially up to $45 \%$ of the carcass value are responsible for large economic losses due to bovine cysticercosis. In England alone bovine cysticercosis is estimated to cost $\$ \$ 5.6$ million annually although the largest economic burden is imposed upon Africa, where it is estimated that $\backslash \$ 1.8$ billion is lost annually (Abuseir et al., 2006).

\subsection{Taxonomic Classification of the Agent(s)}

\subsubsection{Taxonomy and physical description of the agents}

There are two major subclasses of tapeworms, Cestodaria and Eucestoda. The genus Taenia belong to the subclass Eucestoda, order Cyclophilyllidea and family Taenidae. The family Taenidae comprises small to large sized tapeworms. Tapeworms are anchored to the intestine of the host by a holdfast organ named scolex and possess a large tape-like body with segments, called proglottids. There is no alimentary canal and each segment has both female and male sexual organ. The eggs of Taenia spp. are small 34 to $36 \mu \mathrm{m}$ and subspherical and cannot easily be identified to the species level morphologically. Almost all the Cyclophyllidean family includes parasites that have two hosts. Their life cycles always involve vertebrate and invertebrate species for the adult and intermediate forms, respectively (Smith, 1969). Taeniids are unique among the cyclophyllideans in having mammals as both definitive and intermediate hosts.

\subsection{Transmission}

\subsubsection{Life cycle, and routes of transmission}

The life cycle of T. solium, saginata and asiatica involve humans as the sole definitive hosts, harbouring the adult tapeworm in the intestine. T. saginata adult tapeworms produce 1,000 to 2,000 proglottids per worm and may produce up to 100,000 eggs per worm. T. solium (pork) produce an average of 1,000 proglottids/worm, and may produce 50,000 eggs per worm and T. asiatica tapeworms produce 700 proglottids/worm and may produce 80,000 eggs per proglottid. The metacestode (larval) stage of the parasites is found in pigs, in the case of T. solium and $T$. asiatica and in cattle and some other ruminants in the case of T. saginata (Flisser et al., 2004; Galan-Puchades and Fuentes, 2013). Transmission between intermediate and definitive host occurs through ingestion of undercooked meat containing metacestodes, with transmission from definitive host and intermediate host occurs through the ingestion of the eggs or egg-filled proglottids excreted by the definitive host.

\subsubsection{Dispersion of Taenia spp. eggs}

The way in which the intermediate hosts ingest cestode eggs depends on physiological characteristics of the tapeworms. In T. saginata, the beef tapeworm, proglottids are released one by one and they move away from faeces by contracting and expanding longitudinally towards areas where the eggs may be likely to be ingested by cattle (Flisser et al., 2004). Like other cestodes whose adult form infects ruminants, eggs remain within a range of about 180 $\mathrm{m}$ of the site of faecal deposition but some eggs rapidly disperse in all directions (Gemmell et al., 1987). On the other hand, dispersion of $T$. solium proglottids and eggs is less likely to occur due to the intermittent release nature of non-motile proglottids (Garcia et al., 2003). Therefore, $T$. solium proglottids are usually ingested directly at the site of deposition by the intermediate hosts (Gonzalez et al., 2005).

\subsubsection{Invertebrates and Taenia spp. transmission}

Taenia spp. eggs have been identified in the external body surface and the gut contents of non-biting cyclorrhaphan flies in slum areas of Addis Ababa (Getachew et al., 2007). Experiments have shown that dead blowflies containing eggs of Taenia hydatigena can transmit infection if ingested by lambs during grazing (Lawson and Gemmell, 1985). Consumption by pigs or cattle of Taenia spp. egg-carrying flies may also be a transmission route for $T$. solium and $T$. saginata resulting in porcine or bovine cysticercosis. Eggs of Taenia spp. have been isolated from the gut contents of three $C$. megacephala flies caught on a garbage dump in Nigeria (aAdenusi and Adewoga, 2013). Transmission of eggs by adult flies may occur via A) mechanical dislodgment from the exoskeleton; B) fecal deposition; and C) regurgitation (Graczyk et al., 2001). Oribatid mites may also be involved 
in transmission, with the mites potentially consuming tapeworm eggs released in the faeces of definitive hosts and intermediate host potentially acquiring the tapeworm larvae through accidental ingestion of infected mites during grazing (Mullen and OConnor, 2002).

\subsubsection{Dung Beetles and Parasite eggs}

The ability of dung beetles to act as passive vectors carrying Taenia eggs was first suggested by Bily (Bily et al., 1978) and the potential of Dermestes maculatus to passage T. saginata eggs was suggested by Prokopic (Prokopic and Minar, 1980). These results were later confirmed with an experiment which demonstrated that two genus of paracoprid beetle from Kenya, Onitis spp. and Heliocopris spp., remained infected with T. saginata eggs for up to 10 days (Mutinga, 1981). The tenebrid beetle Ammophorus rubripes, also coprophagic, can harbour intact $T$. solium eggs for 36 days after ingestion (Gomez-Puerta et al., 2014). Pigs have been demonstrated to eat dung beetles when consuming feces (Gonzales, 2010) and beetles are abundantly attracted to human stools suggesting a possible role of dung beetles within Taenia spp. transmission.

\subsection{Population and Individual Control Measures}

There are various proposed methods for control of Taenia spp. at a population level. For discussion of the measures and their efficacy we refer readers to the following reviews: (Carabin and Traoré, 2014; Thomas, 2015; Okello and Thomas, 2017).

\subsubsection{Hygiene measures}

Poor hand hygiene, such as not using soap to wash hands after defecation, has been associated with greater risk of exposure to cysticercosis (Vora et al., 2008) and therefore education encouraging better personal hygeine practices are important in the control of $T$. solium (Alexander et al., 2011).

\subsubsection{Drug and Treatment options}

\subsubsection{Human taeniosis}

Infections with the adult stage of Taenia spp. are responsive to the common anthelmintic drugs, niclosamide (2g/person as a single dose), praziquantel (5-10mg/kg as a single dose)(Pearson and Guerrant, 1983, Pearson and Hewlett, 1985) and Albendazole (3x400mg/person for three consecutive days) (Steinmann et al., 2011). All treatments have demonstrated between 85 to $100 \%$ efficacy (Steinmann et al., 2011) (Pawlowski et al., 2005) with Paziquantel appearing to be the most cost-effective treatment at $\$ 0.05$ to 0.1 /person (Engels et al., 2003). Reported minor side-effects of praziquantel are abdominal pain, dizziness and diarrhoea (Raso et al., 2004) though there are also concerns that, due to the ability of praziquantel to cross the blood-brain barrier (BBB), there may be neurological consequences due to an inflammatory response to the death of previously undiagnosed NCC (Flisser et al., 2003). Neurological side-effects are a potential danger in Albendazole treatment which also crosses the BBB (Sotelo and Jung, 1998). Niclosamide, conversely has little systemic absorption and therefore has no effect on NCC (Pawlowski, 2006).

\subsubsection{Human Cysticercosis}

A full discussion of treatment of human cysticercosis is beyond the scope of this chapter. Several recent reviews have provide a good overview of the disease, its symptomology and its treatment. (Garcia et al., 2014; WHO, 2015; Gripper and Welburn, 2017)

\subsubsection{Porcine and Bovine Cysticercosis}

Treatment of the larval stage of Taenia solium can be achieved through the use of anthelmintic treatment, with Oxfenbendazole $(30 \mathrm{mg} / \mathrm{kg})$ demonstrating the best efficacy (Gonzales et al., 1996 ; Gonzalez et al., 1997, 1998; Gonzalez et al., 2001; Sikasunge et al., 2008). Oxfendazole has no reported side-effects (Gonzalez et al., 1998), has now been approved in many countries and is now being formulated specifically as Panthic 10\% for this indication in pigs (Thomas, 2015). It has been suggested that treatment of pigs with oxfendazole could be utilised as a control strategy and some evidence exists for of its utility when used in combination with human MDA (Garcia et al., 2006) and/or concurrent use of a porcine vaccination against $T$. solium (Assana et al., 2010; Okello et al., 2016). Bovine cysticercosis also responds to anthelmintic treatment with praziquantel (Pawlowski et al., 1978; Thomas and Gönnert, 1978; Harrison et al., 1984) and protection against reinfection appears to last at least 12 weeks (Gallie and Sewell, 1983)

\subsubsection{4 .Vaccines}

Vaccines have been developed against the larval infection in the porcine host and two of these (SP3VAC and TSOL18) have shown high efficacy in protecting pigs from both experimental and natural challenges (Lightowlers, 1999; Plancarte et al., 1999; Huerta et al., 2001; Gonzalez et al., 2005; Sciutto et al., 2007a, 2007b; Morales et al., 2008; Lightowlers, 2010; Morales et al., 2011; Jayashi et al., 2012). Vaccination of cattle against $T$. saginata has been attempted with some success, with the TSA9/TSA18 vaccine demonstrating high efficacy in protecting cattle from infection (Rickard et al., 1981; Lightowlers et al., 1996, 2000; Harrison et al., 2005).

\subsection{ENVIRONMENTAL OCURRENCE AND PERSISTENCE}

Key to the propagation of the Taenia spp. lifecycle is the contact between the intermediate hosts (cattle, pigs) and human faecal material containing infective eggs. Sanitation measures such as the use of well-constructed latrines, correct management of excreta and waste water and best practise in animal husbandry all contribute to preventing the intermediate host (or accidental intermediate host in the case of $T$. solium) becoming infected. Best practise in meat hygiene, including meat inspection and correct 
cooking techniques can prevent infection in the definitive (human) host. In the case of T. solium, human cysticercosis infections can be prevented through stringent hand hygiene to prevent faecal-oral contamination with the infective eggs.

Free-range pigs are often more at risk from infection with Taenia spp. than those which are kept under confined conditions (Sarti et al., 1992; Sikasunge et al., 2007; Pondja et al., 2010) and an increase in the popularity of free-range pork in Europe is identified as having the potential to increase the prevalence of porcine cysticercosis found in that region (Zammarchi et al., 2013). Housed cattle and pigs can also be exposed however, through fodder contaminated by slurry containing Taenia spp. eggs or due to family or farm workers defecating in the housing unit (Ilsoe et al.,1990; Sarti et al., 1992; Dorny et al., 2002; Shey-Njila et al., 2003).

The absence of a latrine on the homestead has been identified as a risk factor for porcine cysticercosis (Sánchez et al., 1998; Shey-Njila et al., 2003; Ngowi et al., 2004; Mutua et al., 2007; Kagira et al., 2010; Eshitera et al., 2012) as members of the homestead will out of necessity, engage in open defecation, therefore allowing free-ranging pigs easy access to potentially infective human excreta. It has been hypothesised that the practice of open defecation may been associated with outbreaks of bovine cysticercosis in New Zealand (McFadden et al., 2011). Improvements in sanitation have been hypothesised to be responsible for the reduction in NCC cases in Ecuador between 1990 to 2009 (Del Brutto et al., 2012) but there is not yet evidence for successful control of $T$. solium through use of specific latrine provision (Bulaya et al., 2015; Thomas, 2015). Focus group discussions with a community in Zambia where a program of 'community lead total sanitation' was undertaken, identified several barriers to the use of latrines. Barriers to use included taboos surrounding the use of latrines by men if in-laws or grown up children of the opposite sex use the same latrine (Thys et al., 2015). Studies such as this illustrate the importance of taking into account cultural norms when designing and implementing programs aiming to improve the sanitation of communities.

If sanitation infrastructure is available, the correct management of the resultant treated waste-water and sludge is incredibly important for the control of Taenia spp. as illustrated by the association of access of cattle to surface water and close proximity of waste water effluent with bovine cysticercosis in Belgium (Boone et al., 2007).

\subsection{Detection Methods}

Taenia spp. ova have a specific gravity of 1.27 (Maya et al., 2006). Modified flotation and sedimentation techniques have successfully recovered Taenia spp. eggs from soil (Huerta et al., 2008; Maikai et al., 2008; Nooraldeen, 2015), water (Scandrett and Gajadhar, 2004; Ayed et al., 2009; Verbyla et al., 2013), and sewage sludge (Cabaret et al., 2002) although the techniques have not been standardised. Egg recoveries appear low, with sensitivities of $19-47 \%$ being reported for the most effective triple- flotation method (Cabaret et al., 2002), potentially due to adherence of particulate matter to the egg (Scandrett and Gajadhar, 2004). Eggs of different Taenia spp. cannot be distinguished on appearance (Scandrett and Gajadhar, 2004; Gajadhar et al., 2006; Huerta et al., 2008), molecular methods are available which have been utilised primarily for the diagnosis of Taeniosis, though there is potential that they could be utilised for environmental detection and allow for speciation of the eggs (González et al., 2000). Faust triple flotation technique with ZnSo4.7H20 (728g) plus deionised water to a volume of $1,000 \mathrm{ml}$, sp.G of 1.38 (Barbier et al., 1990) had a mean recovery efficacy (E) of $35 \%$ (95\% C.I. 25.2 to 42.8) (Barbier et al., 1990).

\subsection{Data on Occurrence in the Environment}

\subsubsection{Raw sewage and sludge}

Taenia spp. ova can be found in raw sewage and sewage sludge in all communities in which the helminths are endemic as demonstrated in the examples cited in section 3.0. Yet the numbers are not often reported. In Iran 1.25 eggs/l were found in raw wastewater and 0 eggs/l in the effluent from an activated sludge treatment (Mahvi and Kia, 2006). Another study found 15 eggs/g dry matter of sludge (Keller et al., 2004).

\subsubsection{Surface water including recreational water}

Surface water may easily be contaminated with excreta or raw sewage and in turn with Taenia spp.. Access of cattle to surface water has been identified as a risk factor for bovine cysticercosis in Belgium (Boone et al., 2007) and Taenia spp.-like ova have been detected in water piped from a local stream to a cattle feedlot in Alberta, USA (Scandrett and Gajadhar, 2004).

\subsubsection{Groundwaters}

Contamination of groundwater by Taenia spp. is unlikely due to the relatively large size of ova (Reynolds and Barrett, 2003).

\subsubsection{Drinking waters}

Taenia spp. ova have been detected in drinking water in Iran (Yousefi et al., 2009) and from peri-urban settlements around Harare, Zimbabwe (Dalu et al., 2011)

\subsubsection{Rainwater harvesting}

The authors know of no reports of Taenia spp. ova detected in freshly harvested rainwater

\subsubsection{Seawater and shellfish}

Taenia spp. are not known to infect fish or shellfish.

\subsubsection{Soil}

Taenia spp. ova have been found in soil samples from 
households in Mexico (Camacho et al., 1991; Huerta et al., 2008) and from public parks in Iraq (Nooraldeen, 2015).

\subsection{Persistence (Survival) of eggs}

It has been suggested that Taenia spp. eggs are one of the most resilient parasites found in excreta (Cabaret et al., 2002). The viability of Taenia spp. eggs is generally assessed by hatching studies where they are incubated using a variety of protocols. After prior incubation in acidified pepsin solution ochospheres are incubated at $37-39^{\circ}$ in artificial intestinal solutions which contain pancreatin, ox or pig bile and sometimes foetal bovine serum. Observing motility or extrusion of hooks from the onchosphere is taken to be indicative of viability. The reduction of MTT (3-(4,5-dimethylthiazol-2-yl)-2,5diphenyltetrazolium bromide) by mitochondrial enzymes with resulting blue staining of eggs has also been used to assess the viability of Taenia spp. eggs (Maravilla et al., 2011) including in sludge (Cabaret et al., 2002). The tenebrid beetle Ammophorus rubripes can harbour intact $T$. solium eggs for 36 days after ingestion (Gomez-Puerta et al., 2014). T. saginata eggs on the soil may remain infective for 5.5 to 9.5 months (Storey and Phillips, 1985; Ilsoe et al., 1990). No T. solium specific data is available but we would assume that the longevity is similar to that of $T$. saginata. The treatment and disposal of waste water from sewage treatment causes a dilution of the eggs explaining the low intensity of most of the infections in cattle in Western Europe. (Dorny et al., 2000).

\subsection{REDUCTIONS BY SANITATION MANAGEMENT}

\subsection{Excreta and wastewater treatment}

\subsubsection{Onsite sanitation}

\subsubsection{Dry onsite sanitation systems}

\subsection{Inactivation by storage}

It is assumed that cold storage of liquid sludge $\left(4^{\circ} \mathrm{C}\right)$ has little inactivation effect on Taenia spp. eggs, with a $0.32 \log _{10}$ reduction (48\% remaining viable) after 60 days. Increasing temperature has the greatest effect upon egg viability with temperatures of $35^{\circ} \mathrm{C}$ leading to $1.4 \log _{10}$ inactivation after 60 days of storage (Storey, 1987). Storage in drying beds appears also to be ineffective at destroying Taenia spp. ova with survival for up to 335 days being reported under cool moist conditions in the UK (Silverman and Griffiths, 1955).

\subsubsection{Pit Latrines, Vault Toilets, Dry Toilets}

Ecosan sludge (created after urine separation) mixed with topsoil and stored for 12 months had $0.06 \log _{10}$ reduction $(88 \%$ of the helminth ova remained viability including Taenia spp. though specific data on Taenia spp. was not available) indicating that there is little inactivation purely through storage at a moisture content of 57\%.(Jimenez et al., 2006). Urine separation in a composting toilet in Burkino Faso with an average temp $37^{\circ} \mathrm{C}-/+2$ and average moisture content $23+/-2 \%$ was found to be poor conditions for inactivation of helminths and therefore post-composting heat treatment of at least $50^{\circ} \mathrm{C}$ with moisture contents of $<50 \%$ is strongly suggested (Darimani et al., 2016). The addition of quicklime (15\%) resulted in 0.46 to $1.1 \log _{10}$ (65 to $92 \%$ ) inactivation with $2 \mathrm{hr}$ contact time (Mendez et al., 2002). The addition of the ovicidal fungi Pochonia chlamydosporia has demonstrated efficacy in the inactivation of $T$. sagniata. The fungus, which is a natural commensal organism of soil, appears to penetrate and attack the eggs via enzymatic activity. (Silva and Costa-Cruz, 2010).

\subsection{Composting and ensilation}

Thermal composting with temperatures over $45^{\circ} \mathrm{C}$ has been recommended as a method to disinfect faecal waste. The reduction in the number of tapeworm eggs is inversely proportional to the time and the final silage temperature (Vinnerås et al., 2003). The effect of ensilation (acid treatment) on Taenia spp. eggs has been modelled using Taenia hydatigena eggs ensiled in minced potatoes at $22^{\circ} \mathrm{C}$ for $0,7,14,21$ and 28 days before being fed to lambs. No cysticerci were detected in the lambs at slaughter and regression analysis suggested that 18.6 days of should achieve a reduction of $3 \log _{10}(99.9 \%)$ in viability (Buttar et al., 2013).

\subsubsection{Water-based onsite sanitation systems}

Septic tank sludge appears to be responsible for several large outbreaks of bovine cysticercosis in Denmark (Ilsoe et al., 1990). Data are currently lacking on the viability of Taenia spp. eggs after septic tank storage, but evidence from Ascaris spp. indicates that periods of at least 24 months of storage may be needed (Pompeo et al., 2016). Various factors can interfere with the efficiency of a septic tank such as high volumes of rainwater contributing to a sudden increased inflow volume, resulting in dilution of the sludge interfering with the decomposition process (Silverman and Griffiths, 1955).

\subsubsection{Waste stabilization ponds and aerated lagoons}

Although successful removal of Taenia spp. eggs has been demonstrated through stabilisation in Brazil (Ayres et al., 1993) and Thailand (Wongworapat et al., 2001), ova, including those of $T$. solium, have been detected in the effluent from stabilisation pond systems in Bolivia (Verbyla et al., 2013) and Tunisia (Ayed et al., 2009). This may be due to the increased use of detergents, which interferes with sedimentation processes, allowing eggs to pass relatively freely into the effluent (Kyvsgaard and Murrell, 2005).

Aerated lagoons utilise heat production through exothermic degradation of organic matter by aerobic thermophilic microbes within the slurry mixture and can achieve temperatures between 55 to $70^{\circ} \mathrm{C}$. The efficacy of Taenia spp. inactivation depends upon a combination of time and temperature, with eggs being eliminated by exposure to treatments $>60^{\circ} \mathrm{C}$ for 15 minutes and $>70^{\circ} \mathrm{C}$ for 
5 minutes. In theory, therefore, Taenia spp. should be eliminated by a typical $24 \mathrm{hr}$ period in an aerated lagoon (Mohaibes and Heinonen-Tanski, 2004)

\subsubsection{Constructed Wetlands}

The use of constructed wetlands has been studied outside Marrakech city (Morocco). Reeds were planted at a density of 5 shoots per square metre onto a substratum of organic soil (ph near 7) and superficial soil layer of approximately $1 / 3$ clay, $1 / 3$ silt and $1 / 3$ sand. Four beds were constructed of $20,30,40$ and $50 \mathrm{~m}$, they were irrigated weekly and the retention time varied between 1 and 4 hours depending on the bed length. All samples of untreated waste water contained helminth eggs with $8 \%$ of samples containing Taenia spp. eggs and the efficacy of helminth egg removal was contingent on bed length. The helminth eggs appear to be removed by sedimentation, with rhizomes and submerged reed stalks enhancing sedimentation by blocking the egg outflow. The $20 \mathrm{~m}$ bed removed only $71 \%$ of helminth eggs with the $50 \mathrm{~m}$ bed removing $1.3 \log _{10}$ of helminth eggs and removal $>2 \log _{10}$ has been demonstrated by a combination of $24 \mathrm{~m}$ wetland with a horizontal flow gravel bed although the Taenia spp. specific efficacy was not reported in any study (Mandi et al., 1998; Jimenez, 2007).

\subsubsection{Wastewater Treatment and Resource Recovery Facilities}

\subsubsection{Primary /preliminary treatment}

Experimental data using an 18-inch column of raw sewage, found that 15 minutes of sedimentation removed $0.3 \log _{10}$ of $T$. saginata eggs, rising to $1.7 \log _{10}$ removal after 120 minutes (Newton et al., 1949). Alternative data reported $0.49 \log _{10}$ reduction due to settlement of $T$. saginata eggs from raw sewage within $2 \mathrm{hrs}$ and $0.96 \log _{10}$ reduction within 3 hrs although detergent content, currents and disturbances in the settling basin can affect the efficacy (Hays, 1977).

Chemically enhanced primary treatment (CEPT), utilises chemicals such as lime to cause coagulation-flocculation, which in turn accelerates the sedimentation of helminth ova into the sludge and has demonstrated 1 to $2 \log _{10}$ egg removal (Jimenez, 2007).

\subsubsection{Secondary treatment}

\subsection{Trickling filters}

Experimental data from the 1940s suggest that gravel (3.5 ft depth of 1.5" gravel) trickle filters loaded at 0.27 to 0.33 lbs biological oxygen demand with a filtration of 3 to $4 \mathrm{hrs}$, were not very effective at removing Taenia saginata eggs from waste water removing only $0.15 \log _{10}$ to $0.21 \log _{10}$ of eggs (Newton et al., 1949). For helminth eggs in general efficacies of only $0.3 \log _{10}$ up to $1.3 \log _{10}$ reductions have been reported for trickling filtration (including sedimentation, sludge digestion and sludge drying) (Feachem et al., 1983).

\subsection{Activated sludge}

In Iran 1.25 eggs/l were found in raw wastewater and 0 eggs/l in the effluent from an activated sludge treatment (Mahvi and Kia, 2006) and Taenia spp. ova were also successfully removed from treated effluent in Thailand (Wongworapat et al., 2001). In Tunisia, however $0.89 \log _{10}$ removal (13\% (95\% C.I. 0-38\%) passing through treatment) was observed of Taenia spp. ova by examining the effluent (Ayed et al., 2009). Data from the 1980's suggests that for helminth eggs in general removals of $0.3 \log _{10}$ to $1.0 \log _{10}$ of eggs has been reported by activated sludge including the sedimentation, digestion and drying processes (Feachem et al., 1983).

\subsubsection{Anaerobic/ anoxic digestion and biogas}

Laboratory scale (1.5 gallon) anaerobic digestion at room temperature was found to be ineffective in destroying T. saginata ova for up to 1 months. By 2 months, viability, as assessed by morphological changes, was found to decrease by $0.3 \log _{10}$ and continued to gradually decrease thereafter with only $30 \%$ of eggs recovered having a 'normal' appearance by 203 days in the digester (Newton et al., 1949). Efficacy of anaerobic digestion appears to be dependent on temperature, the situation of the ova (free or bound in proglottids) as well as whether the process is continuous or batch. Digestion at $24-30^{\circ} \mathrm{C}$ was found to result in $1.5 \log _{10}$ reduction (3\% survival) of $T$. saginata at 6 months (Hays, 1977) compared to a $3 \log _{10}$ and greater reduction efficacy after 28 days at $35^{\circ} \mathrm{C}$ (Cabaret et al., 2002). The effect of eggs bound in proglottids was shown in another study with laboratory scale anaerobic digestion at $20^{\circ} \mathrm{C}$ leading to $2.4 \log _{10}$ reduction of initial inoculum of free eggs being viable at 52 days whereas some proglottidbound eggs were found to still be viable at 88 days. The same study also indicated that continuous digestion at $35^{\circ} \mathrm{C}$ was more effective than batch digestion at the same temperature, with no viable eggs found after 10 days of continuous digestion in comparison to some viable eggs remaining after 30 days of batch digestion (Storey, 1987).

\subsubsection{Up-flow Anaerobic Sludge Blanket (UASB)}

The UASB reactor removes helminth eggs through a combination of sedimentation and egg entrapment within the sludge bed. A laboratory scale UASB with $8 \mathrm{hr}$ retention time, demonstrated total removal of helminth eggs (ElGohary and Nasr, 1999) with another laboratory scale reactor demonstrating $93=/-5 \%$ removal at low up-flow rates of $0.9 \mathrm{~m} . \mathrm{h}-1$, though decreasing in a linear fashion with increasing up-flow rate (Yaya-Beas et al., 2015).This efficacy has not been replicated in the real world, an investigation in Brazil indicated a $0.6 \log _{10}$ reduction efficacy of the UASB unit with retention time of $5.5 \mathrm{hrs}$ in removing helminth eggs (no Taenia spp. present in the raw sewage) and in combination with a baffled polishing pond resulted in complete removal of helminth eggs in 13 of 14 effluent samples with a mean of 0.1 helminth egg/l across all samples (Von Sperling et al., 2002). A study in Bolivia found poor efficacy of a UASB in removing helminth ova with only $0.11 \log _{10}$ of ova removed with $30 \%$ of the ova in 
the USAB effluent being viable. In this study $78.9 \%$ of ova in the raw sewage inflow were identified as Taenia spp., and both Taenia spp. and Ascaris spp. were detected in the system effluent (Verbyla et al., 2013). This indicates that a USAB is not sufficient to remove Taenia spp. and must be combined with post-treatment.

\subsubsection{Filtration}

Studies of working rapid sand filtration systems in Coventry (UK) in the 1950's found that the current operational practises were insufficient to remove Taenia spp. ova. At a flow of 1400 gallons per hour through sand 2 feet deep T. saginata ova were recovered in 13 of 14 samples of the effluent taken between 5 and 130 minutes of addition of the ova to the inflow and over $0.3 \log _{10}$ removal of the total ova introduced to the filter when examining the final effluent (Silverman and Griffiths, 1955). The speed of filtration, effective particle size and depth of sand however does influence the efficacy of sand filtration systems with slow sand filtration systems around Johannesburg (SA) appearing to remove all Taenia spp. ova from the effluent (Newton et al., 1949). Laboratory studies demonstrated removals of 3 to $>3 \log _{10}$ of $T$. saginata ova, with sand of $0.5 \mathrm{~mm}$ effective size and 2.2 uniformity coefficient and a filtration rate of $1,000,000$ gallons per acre per day (Newton et al., 1949).

\subsubsection{Membranes. Micro, Ultra And Reverse Osmosis}

Membrane technologies such as micro filtration, using a very finely woven fabric of stainless steel were introduced to the UK in 1945 and experimental evidence from the 1950 's suggests they are capable of removing $90 \%$ of $T$. saginata ova (Silverman and Griffiths, 1955). There is some evidence that membrane bioreactors produce effluent with $<1$ helminth egg/l (Moeslang and Brockmann). Dual-media filtration is estimated to have a theoretical removal rate of approximately $2 \log _{10}$ of helminth ova (Jimenez-Cisneros and Maya-Rendon, 2007).

\subsubsection{Land treatment}

Cysticercosis due to $T$. saginata appears to be one of the major pathological threats when sewage sludge is used to fertilise cattle pastures in temperate areas. Land application of sludge is inefficient in destroying the eggs of Taenia spp. with reports of eggs remaining viable on grass for up to 159 days (Straub et al., 1993; Cabaret et al., 2002).

\subsection{Disinfection as Tertiary (Post Primary) Treatment}

\subsubsection{Chemical}

Treatment of raw sewage sludge with an initial concentration of $15 \mathrm{egg} / \mathrm{g}$ dry matter with quicklime at 30 to $60 \%$ was found to eliminate helminth eggs. Concentrations of 10 to $20 \%$ quicklime resulted in a few non-viable heminth eggs being detected (Keller et al. 2004) Chlorination of wastewater has been reported to achieve no inactivation up to to $0.1 \log _{10}$ inactivation of helminth ova under laboratory conditions as reviewed by (JimenezCisneros and Maya-Rendon 2007).

\subsubsection{Ultraviolet}

There are no data currently available on the efficacy of UV irradiation on T. solium.

\subsubsection{Pasteurization}

Pasteurization at 65 to $70^{\circ} \mathrm{C}$ for 15 to 30 minutes has been reported to inactivate $>2 \log _{10}$ of helminth ova from sludge (Keller et al., 2004; Paulsrud et al., 2004) 


\section{References}

Abuseir, S., Epe, C., Schnieder, T., Klein, G. and Kühne, M. (2006). Visual diagnosis of Taenia saginata cysticercosis during meat inspection: is it unequivocal?. Parasitology research. 99, pp. 405-409.

Adenusi, A.A. and Adewoga, T.O. (2013). Studies on the potential and public health importance of non-biting synanthropic flies in the mechanical transmission of human enterohelminths. Transactions of the Royal Society of Tropical Medicine and Hygiene. 107(12), pp. 812-818.

Alexander, A., John, K.R., Jayaraman, T., Oommen, A., M. Raghava, V., Dorny, P. et al. (2011). Economic implications of three strategies for the control of taeniasis. Tropical Medicice and International Health. 16, pp. 1410-1416. doi: 10.1111/j.1365-3156.2011.02850.x.

Assana, E., Kyngdon, C.T., Gauci, C.G., Geerts, S., Dorny, P., De Deken, R. et al. (2010). Elimination of Taenia solium transmission to pigs in a field trial of the TSOL18 vaccine in Cameroon. International journal for parasitology. 40, pp. 515-519.

Atef, M. and Emna, T. (2015). A Rare Cause of Intestinal Obstruction. Journal of Clinical Case Reports. 5, pp. 2.

Ayres, R.M., Lee, D.L., Mara, D.D. and Silva, S.A. (1993). The accumulation, distribution and viability of human parasitic nematode eggs in the sludge of a primary facultative waste stabilization pond. Transactions of the Royal Society of Tropical Medicine and Hygiene. 87, pp. 256-258.

Bílý, S., Stĕrba, J. and Dyková, I. (1978). Results of an artificial feeding of eggs of Taenia saginata Goeze, 1782 to various beetle species. Folia Parasitol (Praha). 25(3), pp. 257-260.

Barbier, D., Perrine, D., Duhamel, C., Doublet, R. and Georges, P. (1990). Parasitic hazard with sewage sludge applied to land. Applied and environmental microbiology. 56, pp. 1420-1422.

Ben Ayed, L., Schijven, J., Alouini, Z., Jemli, M. and Sabbahi, S. (2009). Presence of parasitic protozoa and helminth in sewage and efficiency of sewage treatment in Tunisia. Parasitology research. 105, pp. 393-406.

Boone, I., Thys, E., Marcotty, T., De Borchgrave, J., Ducheyne, E. and Dorny, P. (2007). Distribution and risk factors of bovine cysticercosis in Belgian dairy and mixed herds. Preventive veterinary medicine. 82, pp. 1-11.

Braae, U.C., Saarnak, C.F., Mukaratirwa, S., Devleesschauwer, B., Magnussen, P. and Johansen, M.V. (2015). Taenia solium taeniosis/cysticercosis and the co-distribution with schistosomiasis in Africa. Parasites and Vectors. 8, pp. 323.

Bruno, E., Bartoloni, A., Zammarchi, L., Strohmeyer, M., Bartalesi, F., Bustos, J.A. et al. (2013). Epilepsy and Neurocysticercosis in Latin America: A Systematic Review and Meta-analysis. PLOS Neglected Tropical Diseases. 7, pp. e2480. doi: 10.1371/journal.pntd.0002480.

Bulaya, C., Mwape, K.E., Michelo, C., Sikasunge, C.S., Makungu, C., Gabriel, S. et al. (2015). Preliminary evaluation of Community-Led Total Sanitation for the control of Taenia solium cysticercosis in Katete District of Zambia. Veterinary parasitology. 207, pp. 241-248.

Buttar, B.S., Nelson, M.L., Busboom, J.R., Hancock, D.D., Walsh, D.B. and Jasmer, D.P. (2013). Effect of ensilation of potato on viability of Taenia hydatigena eggs. Experimental parasitology. 133, pp. 483-486.

Cabaret, J., Geerts, S., Madeline, M., Ballandonne, C. and Barbier, D. (2002). The use of urban sewage sludge on pastures: the cysticercosis threat. Veterinary Research. 33, pp. 575-597.

Camacho, S.P.D., Ruiz, A.C., Peraza, V.S., Ramos, M.L.Z., Medina, M.F., Lozano, R. et al. (1991). Epidemiologic study and control of Taenia solium infections with praziquantel in a rural village of Mexico. The American journal of tropical medicine and hygiene. 45 , pp. 522-531.

Cantey, P.T., Coyle, C.M., Sorvillo, F.J., Wilkins, P.P., Starr, M.C. and Nash, T.E. (2014). Neglected parasitic infections in 
the United States: cysticercosis. The American Journal of Tropical Medicine and Hygiene. 90(5), pp. 805-809.

Carabin, H. and Traoré, A.A. (2014). Taenia solium taeniasis and cysticercosis control and elimination through communitybased interventions. Current tropical medicine reports. 1, pp. 181-193.

Coral-Almeida, M., Gabriel, S., Abatih, E.Nji, Praet, N., Benitez, W. and Dorny, P. (2015). Taenia solium Human Cysticercosis: A Systematic Review of Sero-epidemiological Data from Endemic Zones around the World. PLOS Neglected Tropical Diseases. 9, pp. e0003919.

Dalu, T., Barson, M. and Nhiwatiwa, T. (2011). Impact of intestinal microorganisms and protozoan parasites on drinking water quality in Harare, Zimbabwe. Journal of Water Sanitation and Hygiene for Development. 1, pp. 153-163.

Darimani, H.S., Ito, R., Maiga, Y., Sou, M., Funamizu, N. and Maiga, A.H. (2016). Effect of post-treatment conditions on the inactivation of helminth eggs (Ascaris suum) after the composting process. Environmental Technology. 37, pp. 920-928.

DeGiorgio, C., Pietsch-Escueta, S., Tsang, V., Corral-Leyva, G., Ng, L., Medina, M.T. et al. (2005). Sero-prevalence of Taenia solium cysticercosis and Taenia solium taeniasis in California, USA. Acta Neurologica Scandinavica. 111(2), pp. 84-88.

Del Brutto, O.H. and Garcia, H.H. (2012). Taenia solium cysticercosis: new challenges for an old scourge. Pathogens and Global Health. 106, pp. 253-253. doi: 10.1179/2047772412Z.00000000071.

Devleesschauwer, B., Allepuz, A., Dermauw, V., Johansen, M.V., Laranjo-González, M., G Smit, S.A. et al. (2015). Taenia solium in Europe: Still endemic?. Acta tropica.

Dorny, P., Phiri, I., Gabriel, S., Speybroeck, N. and Vercruysse, J. (2002). A sero-epidemiological study of bovine cysticercosis in Zambia. Veterinary parasitology. 104, pp. 211-215.

Dorny, P., Vercammen, F., Brandt, J., Vansteenkiste, W., Berkvens, D. and Geerts, S. (2000). Sero-epidemiological study of Taenia saginata cysticercosis in Belgian cattle. Veterinary parasitology. 88, pp. 43-49.

El-Gohary, F.A. and Nasr, F.A. (1999). Cost-effective pre-treatment of wastewater. Water Science and Technology. 39, pp. 97-103.

Engels, D., Urbani, C., Belotto, A., Meslin, F. and Savioli, L. (2003). The control of human (neuro)cysticercosis: which way forward?. Acta Tropica. 87, pp. 177-182.

Eshitera, E.E., Githigia, S.M., Kitala, P., Thomas, L.F., Fèvre, E.M., Harrison, L.J.S. et al. (2012). Prevalence of porcine cysticercosis and associated risk factors in Homa Bay District, Kenya. BMC Veterinary Research. 8, pp. 234.

Feachem, R., Mara, D. and Bradley, D.J. (1983). Sanitation and disease. John Wiley and Sons. Washington DC, USA.

Flisser, A. (2006). Where are the tapeworms. International Journal for Parasitology. 55 Suppl, pp. S117-120.

Flisser, A., Viniegra, A.E., Aguilar-Vega, L., Garza-Rodriguez, A., Maravilla, P. and Avila, G. (2004). Portrait of human tapeworms. Journal of Parasitology. 90(4), pp. 914-916.

Flisser, A., Craig, P.S. and Ito, A. (2011). Cysticercosis and taeniosis: Taenia solium, Taenia saginata and Taenia asiatica. Oxford Textbook of Zoonoses: Biology, Clinical Practice, and Public Health Control. Oxford University Press, Oxford. pp. 625-642.

Flisser, A., Sarti, E., Lightowlers, M. and Schantz, P. (2003). Neurocysticercosis: regional status, epidemiology, impact and control measures in the Americas. Acta Tropica. 87, pp. 43-51. doi: http://dx.doi.org/10.1016/S0001-706X(03)00054-8.

Gajadhar, A.A., Scandrett, W.B. and Forbes, L.B. (2006). Overview of food-and water-borne zoonotic parasites at the farm level. Revue scientifique et technique. 25, pp. 595-606.

Galan-Puchades, M.T. and Fuentes, M.V. (2013). Lights and shadows of the Taenia asiatica life cycle and pathogenicity. 
Tropical Parasitology. 3(2), pp. 113-119.

Gallie, G.J. and Sewell, M.M. (1983). Duration of immunity and absorption of cysticerci in calves after treatment of Taenia saginata cysticercosis with praziquantel. Research in veterinary science. 34, pp. 127-130.

Garcia, H.H., Nash, T.E. and Del Brutto, O.H. (2014). Clinical symptoms, diagnosis, and treatment of neurocysticercosis. The Lancet Neurology. 13, pp. 1202-1215.

Garcia, H.H., Gonzalez, A.E., Evans, C.A.W. and Gilman, R.H. (2003). Taenia solium cysticercosis. The Lancet. 362, pp. 547-556.

Garcia, H.H., Gonzalez, A.E., Gilman, R.H., Moulton, L.H., Verastegui, M., Rodríguez, S. et al. (2006). Combined human and porcine mass chemotherapy for the control of T. solium. The American Journal of Tropical Medicine and Hygiene. 74, pp. 850-5.

Gemmell, M.A.,,. and Roberts, M.G. (1987). Population dynamics in echinococcosis and cysticercosis: evaluation of the biological parameters of Taenia hydatigena and T. ovis and comparison with those of Echinococcus granulosus. Parasitology. 94(1), pp. 161-180.

Getachew, S., Gebre-Michael, T., Erko, B., Balkew, M. and Medhin, G. (2007). Non-biting cyclorrhaphan flies (Diptera) as carriers of intestinal human parasites in slum areas of Addis Ababa, Ethiopia. Acta Tropica. 103(3), pp. 186-194.

Gomez-Puerta, L.A., Lopez-Urbina, M.T., Garcia, H.H. and Gonzalez, A.E. (2014). Longevity and viability of Taenia solium eggs in the digestive system of the beetle Ammophorus rubripes. Revista Brasileira de Parasitologia Veterinária. 23, pp. 94-97.

Gonzales, A.E., Garcia, H.H., Gilman, R.H., Gavidia, C.M., Tsang, V.C., Bernal, T. et al. (1996). Effective, single-dose treatment or porcine cysticercosis with oxfendazole. The American journal of tropical medicine and hygiene. 54, pp. 391-394.

Gonzales, E. (2010). Deteccion de huevos de Taenia solium en el intestino de escarabajos coprofagos mediante PCR. Universidad Nacional Mayor de San Marcos.

Gonzalez, A.E., Gavidia, C., Falcon, N., Bernal, T., Verastegui, M., Garcia, H.H. et al. (2001). Protection of pigs with cysticercosis from further infections after treatment with oxfendazole. American Journal of Tropical Medicine and Hygiene. 65, pp. 15-18.

Gonzalez, A.E., Falcon, N., Gavidia, C., Garcia, H.H., Tsang, V.C., Bernal, T. et al. (1998). Time-response curve of oxfendazole in the treatment of swine cysticercosis. The American journal of tropical medicine and hygiene. 59, pp. 832.

Gonzalez, A.E., Falcon, N., Gavidia, C., Garcia, H.H., Tsang, V.C., Bernal, T. et al. (1997). Treatment of porcine cysticercosis with oxfendazole: a dose-response trial. The Vetinary Record. 141, pp. 420-2.

Gonzalez, A.E., Gauci, C.G., Barber, D., Gilman, R.H., Tsang, V.C.W., Garcia, H.H. et al. (2005). Vaccination of pigs to control human neurocysticercosis. The American journal of tropical medicine and hygiene. 72, pp. 837.

Gonzalez, A.E., López-Urbina, T., Tsang, B.Y., Gavidia, C.M., Garcia, H.H., Silva, M.E. et al. (2005). Secondary transmission in porcine cysticercosis: description and their potential implications for control sustainability. The American Journal of Tropical Medicine and Hygiene. 73(3), pp. 501-503.

Gonzalez, L.M., Montero, E., Harrison, L.J.S., Parkhouse, R.M.E. and Garate, T. (2000). Differential diagnosis of Taenia saginata and Taenia solium infection by PCR. Journal of clinical microbiology. 38, pp. 737-744.

Government of Kenya (2012). Meat Control Act.

Graczyk, T.K., Knight, R., Gilman, R.H. and Cranfield, M.R. (2001). The role of non-biting flies in the epidemiology of human infectious diseases. Microbes and Infection. 3(3), pp. 231-235. 
Gripper, L.B. and Welburn, S.C. (2017). Neurocysticercosis infection and disease-A review. Acta tropica. 166, pp. $218-224$.

Guerrero-Latorre, L., Gonzales-Gustavson, E., Hundesa, A., Sommer, R. and Rosina, G. (2016). UV disinfection and flocculation-chlorination sachets to reduce hepatitis E virus in drinking water. International Journal of Hygiene and Environmental Health. 219(4-5), pp. 405-11.

Hakeem, S.Y., Rashid, A., Khuroo, S. and Bali, R.S. (2012). Taenia saginata: A rare cause of gall bladder perforation. Case reports in surgery. 2012,.

Harrison, L.J., Gallie, G.J. and Sewell, M.M. (1984). Absorption of cysticerci in cattle after treatment of taenia saginata cysticercosis with praziquantel. Research in veterinary science. 37, pp. 378-380.

Harrison, L.J.S., Garate, T., Bryce, D.M., Gonzalez, L.M., Foster-Cuevas, M., Wamae, L.W. et al. (2005). Ag-ELISA and PCR for monitoring the vaccination of cattle against Taenia saginata cysticercosis using an oncospheral adhesion protein (HP6) with surface and secreted localization. Tropical animal health and production. 37, pp. 103-120.

Hays, B.D. (1977). Potential for parasitic disease transmission with land application of sewage plant effluents and sludges. Water Research. 11, pp. 583-595.

Huerta, M., Avila, R., Jiménez, H.I., Díaz, R., Díaz, J., Huerta, M.E. et al. (2008). Parasite contamination of soil in households of a Mexican rural community endemic for neurocysticercosis. Transactions of the Royal Society of Tropical Medicine and Hygiene. 102, pp. 374-379.

Huerta, M., De Aluja, A.S., Fragoso, G., Toledo, A., Villalobos, N., Hernández, M. et al. (2001). Synthetic peptide vaccine against Taenia solium pig cysticercosis: successful vaccination in a controlled field trial in rural Mexico. Vaccine. 20, pp. 262-266.

Ilsoe, B., Kyvsgaard, N.C., Nansen, P. and Henriksen, S.A. (1990). Bovine cysticercosis in Denmark. Acta Veterinaria Scandinavica. 31, pp. 159-168.

Jayashi, C.M., Kyngdon, C.T., Gauci, C.G., Gonzalez, A.E. and Lightowlers, M.W. (2012). Successful immunization of naturally reared pigs against porcine cysticercosis with a recombinant oncosphere antigen vaccine. Veterinary Parasitology. 188, pp. 261-267. doi: http://dx.doi.org/10.1016/j.vetpar.2012.03.055.

Jiménez-Cisneros, B.E. and Maya-Rendon, C. (2007). Helminths and sanitation. Communicating current research and educational topics and trends in applied microbiology. 1, pp. 60-71.

Jiménez, B. (2007). Helminth ova removal from wastewater for agriculture and aquaculture reuse. Water Science and Technology. 55, pp. 485-493.

Jiménez, B., Austin, A., Cloete, E. and Phasha, C. (2006). Using Ecosan sludge for crop production. Water science and technology. 54, pp. 169-177.

Kagira, J.M., Maingi, N., Kanyari, P.W.N., Githigia, S.M., Ng'ang'a, J.C. and Gachohi, J.M. (2010). Seroprevalence of Cysticercus cellulosae and associated risk factors in free-range pigs in Kenya. Journal of helminthology. 84, pp. 398-403.

Keller, R., Passamani-Franca, R.F., Cassini, S.T. and Goncalves, F.R. (2004). Disinfection of sludge using lime stabilisation and pasteurisation in a small wastewater treatment plant. Water Science and Technology. 50, pp. 13-17.

Kulkarni, A.S., Joshi, A.R., Shere, S.K. and Bindu, R.S. (2014). Appendicular Taeniasis Presenting as Acute Appendicitis a Report of Two Cases with Review of Literature. International Journal of Health Sciences and Research (IJHSR). 4, pp. 194-197.

Kyvsgaard, N.C. and Murrell, K.D. (2005). FAO/WHO/OIE Guidelines for the Surveillance, Prevention and Control of Taeniosis/cysticercosis. World Organization for Animal Health. Paris.

Lawson, J.R. and Gemmell, M.A. (1985). The potential role of blowflies in the transmission of taeniid tapeworm eggs. Parasitology. 91 (Pt.1), pp. 129-143. 
Lightowlers, M.W. (2010). Eradication of Taenia solium cysticercosis: A role for vaccination of pigs. International Journal for Parasitology. 40, pp. 1183-1192.

Lightowlers, M.W., Rolfe, R. and Gauci, C.G. (1996). Taenia saginata: vaccination against cysticercosis in cattle with recombinant oncosphere antigens. Experimental parasitology. 84, pp. 330-338.

Lightowlers, M.W., Flisser, A., Gauci, C.G., Heath, D.D., Jensen, O. and Rolfe, R. (2000). Vaccination against cysticercosis and hydatid disease. Parasitology Today. 16, pp. 191-196.

Lightowlers, M.W. (1999). Eradication of Taenia solium cysticercosis: a role for vaccination of pigs. International journal for parasitology. 29, pp. 811-817.

Li, P., Xu, L., Xiang, J., He, Z., Peng, Z., Cui, B. et al. (2015). Taeniasis Related Frequent Intestinal Obstruction: Case Report and Mini-Review. Journal of Gastroenterology and Hepatology Research. 4, pp. 1455-1458.

Mahvi, A.H. and Kia, E. (2006). Helminth eggs in raw and treated wastewater in the Islamic Republic of Iran.

Maikai, B.V., Umoh, J.U., Ajanusi, O.J. and Ajogi, I. (2008). Public health implications of soil contaminated with helminth eggs in the metropolis of Kaduna, Nigeria. Journal of helminthology. 82, pp. 113-118.

Mandi, L., Bouhoum, K. and Ouazzani, N. (1998). Application of constructed wetlands for domestic wastewater treatment in an arid climate. Water science and technology. 38, pp. 379-387.

Maravilla, P., Garza-Rodriguez, A., Gomez-Diaz, B., Jimenez-Gonzalez, D.Emiliano, Toral-Bastida, E., Martinez-Ocaña, J. et al. (2011). Chinchilla laniger can be used as an experimental model for Taenia solium taeniasis. Parasitology international. 60, pp. 364-370.

Maya, C., Jiménez, B. and Schwartzbrod, J. (2006). Comparison of techniques for the detection of helminth ova in drinking water and wastewater. Water environment research. 78, pp. 118-124.

McFadden, A.M.J., Heath, D.D., Morley, C.M. and Dorny, P. (2011). Investigation of an outbreak of Taenia saginata cysts (cysticercus bovis) in dairy cattle from two farms. Veterinary parasitology. 176, pp. 177-184.

Mendez, J.M., Jimenez, B.E. and Barrios, J.A. (2002). Improved alkaline stabilization of municipal wastewater sludge. Water Science and Technology. 46, pp. 139-146.

Mohaibes, M. and Heinonen-Tanski, H. (2004). Aerobic thermophilic treatment of farm slurry and food wastes. Bioresource technology. 95, pp. 245-254.

Morales, J., De Aluja, A.S., Martinez, J.J., Hernández, M., Rosas, G., Villalobos, N. et al. (2011). Recombinant S3Pvac-phage anticysticercosis vaccine: Simultaneous protection against cysticercosis and hydatid disease in rural pigs. Veterinary Parasitology. 176, pp. 53-58. doi: http://dx.doi.org/10.1016/j.vetpar.2010.10.039.

Morales, J., Martinez, J.J., Manoutcharian, K., Hernández, M., Fleury, A., Gevorkian, G. et al. (2008). Inexpensive anticysticercosis vaccine: S3Pvac expressed in heat inactivated M13 filamentous phage proves effective against naturally acquired Taenia solium porcine cysticercosis. Vaccine. 26, pp. 2899-2905. doi: http://dx.doi.org/10.1016/j.vaccine.2008.03.042.

Mullen, G. and OConnor, B.M. (2002). Mites (Acari). Medical and veterinary entomology. (Mullen, G.D. and Londom, L.A., ed.). Elsevier. pp. 449-516.

Murray, C.J.L., Vos, T., Lozano, R., Naghavi, M., Flaxman, A.D., Michaud, C. et al. (2012). Disability-adjusted life years (DALYs) for 291 diseases and injuries in 21 regions, 1990-2010: a systematic analysis for the Global Burden of Disease Study 2010. The Lancet. 380, pp. 2197-2223.

Mutinga, M.M.G. (1981). The role of coprophagous beetles in the dissemination of taeniasis in Kenya. International Journal of Tropical Insect Science. 1, pp. 379-382. 
Mutua, F.K., Randolph, T.F., Arimi, S.M., Kitala, P.M., Githigia, S.M., Willingham, A.L. et al. (2007). Palpable lingual cysts, a possible indicator of porcine cysticercosis, in Teso District, Western Kenya. Journal of Swine Health and Production. 15, pp. 206.

Ndimubanzi, P.C., Carabin, H., Budke, C.M., Nguyen, H., Qian, Y.J., Rainwater, E. et al. (2010). A systematic review of the frequency of neurocyticercosis with a focus on people with epilepsy. PLoS neglected tropical diseases. 4 , pp. e870.

Newton, W.L., Bennett, H.J. and Figgat, W.B. (1949). Observations on the effects of various sewage treatment processes upon eggs of Taenia saginata. American Journal of Epidemiology. 49, pp. 166-175.

Ngowi, H.A., Kassuku, A.A., Maeda, G.E.M., Boa, M.E., Carabin, H. and Willingham, A.L. (2004). Risk factors for the prevalence of porcine cysticercosis in Mbulu District, Tanzania. Veterinary Parasitology. 120, pp. 275-283.

Nooraldeen, K. (2015). Contamination of public squares and parks with parasites in Erbil city, Iraq. Annals of Agricultural and Environmental Medicine. 22,.

Okello, A.L. and Thomas, L.F. (2017). Human taeniasis: current insights into prevention and management strategies in endemic countries. Risk Management and Healthcare Policy. 10, pp. 107.

Okello, A.L., Thomas, L., Inthavong, P., Ash, A., Khamlome, B., Keokamphet, C. et al. (2016). Assessing the impact of a joint human-porcine intervention package for Taenia solium control: Results of a pilot study from northern Lao PDR. Acta Tropica. 159, pp. 185-191.

Paulsrud, B., Gjerde, B. and Lundar, A. (2004). Full scale validation of helminth ova (Ascaris suum) inactivation by different sludge treatment processes. Water Science and Technology. 49, pp. 139-146.

Pawlowski, Z., Kozakeiwicz, B. and Wroblewski, H. (1978). The efficacy of mebendazole and praziquantel againstTaenia saginata cysticercosis in cattle. Veterinary Science Communications. 2, pp. 137-139.

Pawlowski, Z.S. (2006). Role of chemotherapy of taeniasis in prevention of neurocysticercosis. Parasitology International. 55, Supplement, pp. S105-S109. doi: http://dx.doi.org/10.1016/j.parint.2005.11.017.

Pawlowski, Z., Allan, J. and Sarti, E. (2005). Control of Taenia solium taeniasis/cysticercosis: From research towards implementation. International Journal for Parasitology. 35, pp. 1221-1232.

Pearson, R.D. and Guerrant, R.L. (1983). Praziquantel: a major advance in anthelminthic therapy. Annals of Internal Medicine. 99, pp. 195-8.

Pearson, R.D. and Hewlett, E.L. (1985). Niclosamide therapy for tapeworm infections. Annals of Internal Medicine. 102, pp. 550-1.

Plancarte, A., Flisser, A., Gauci, C.G. and Lightowlers, M.W. (1999). Vaccination against Taenia solium cysticercosis in pigs using native and recombinant oncosphere antigens. International journal for parasitology. 29, pp. 643-647.

Pompeo, R.P., Andreoli, C.V., de Castro, E.A. and Aisse, M.M. (2016). Influence of Long-Term Storage Operating Conditions on the Reduction of Viable Ascaris Eggs in Sewage Sludge for Agricultural Reuse. Water, Air, and Soil Pollution. 227, pp. $1-14$.

Pondja, A., Neves, L., Mlangwa, J., Afonso, S., Fafetine, J., Willingham, A.L. et al. (2010). Prevalence and risk factors of porcine cysticercosis in Angonia District, Mozambique. PLoS neglected tropical diseases. 4, pp. e594.

Prokopic, J. and Minar, J. (1980). Dermestes maculatus de Geer, 1774 (Coleoptera, Dermestidae) as potential distributor of Taenia saginata Goeze, 1782 eggs. Folia Parasitol (Praha). 27, pp. 37-38.

Rajshekhar, V., Joshi, D.D., Doanh, N.Q., Van De, N. and Xiaonong, Z. (2003). Taenia solium taeniosis/cysticercosis in Asia: epidemiology, impact and issues. Acta tropica. 87, pp. 53-60.

Rajshekhar, V., M Raghava, V., Prabhakaran, V., Oommen, A. and Muliyil, J. (2006). Active epilepsy as an index of burden 
of neurocysticercosis in Vellore district, India. Neurology. 67, pp. 2135-2139.

Raso, G., N'Goran, E.K., Toty, A., Luginbühl, A., Adjoua, C.A., Tian-Bi, N.T. et al. (2004). Efficacy and side effects of praziquantel against Schistosoma mansoni in a community of western Côte d'Ivoire. Transactions of the Royal Society of Tropical Medicine and Hygiene. 98, pp. 18-27.

Reynolds, J.H. and Barrett, M.H. (2003). A review of the effects of sewer leakage on groundwater quality. Water and Environment Journal. 17, pp. 34-39.

Rickard, M.D., Arundel, J.H. and Adolph, A.J. (1981). A preliminary field trial to evaluate the use of immunisation for the control of naturally acquired Taenia saginata infection in cattle. Research in veterinary science. 30, pp. 104-108.

Sánchez, A.L., Medina, M.T. and Ljungström, I. (1998). Prevalence of taeniasis and cysticercosis in a population of urban residence in Honduras. Acta tropica. 69, pp. 141-149.

Sarti, E., Schantz, P.M., Plancarte, A., Wilson, M., Gutierrez, I.O., Aguilera, J. et al. (1992). Epidemiological investigation of Taenia solium taeniasis and cysticercosis in a rural village of Michoacan State, Mexico. Transactions of the Royal Society of Tropical Medicine and Hygiene. 88, pp. 49-52.

Scandrett, W.B. and Gajadhar, A.A. (2004). Recovery of putative taeniid eggs from silt in water associated with an outbreak of bovine cysticercosis. The Canadian Veterinary Journal. 45, pp. 758.

Sciutto, E., Morales, J., Martinez, J.J., Toledo, A., Villalobos, M.N., Cruz-Revilla, C. et al. (2007). Further evaluation of the synthetic peptide vaccine S3Pvac against Taenia solium cysticercosis in pigs in an endemic town of Mexico. Parasitology. 134, pp. 129-33. doi: 10.1017/S0031182006001132.

Sciutto, E., Rosas, G., Hernández, M., Morales, J., Cruz-Revilla, C., Toledo, A. et al. (2007). Improvement of the synthetic tri-peptide vaccine (S3Pvac) against porcine Taenia solium cysticercosis in search of a more effective, inexpensive and manageable vaccine. Vaccine. 25, pp. 1368-1378. doi: http://dx.doi.org/10.1016/j.vaccine.2006.10.018.

Shey-Njila, O., Zoli, P.A., Awah-Ndukum, J., Assana, E., Byambas, P., Dorny, P. et al. (2003). Porcine cysticercosis in village pigs of North-West Cameroon. J Helminthol. 77, pp. 351-354.

Sikasunge, C.S., Johansen, M.V., Iii, AL.Willingham, Leifsson, P.S. and Phiri, I.K. (2008). Taenia solium porcine cysticercosis: Viability of cysticerci and persistency of antibodies and cysticercal antigens after treatment with oxfendazole. Veterinary Parasitology. 158, pp. 57-66.

Sikasunge, C.S., Phiri, I.K., Phiri, A.M., Dorny, P., Siziya, S. and Iii, AL.Willingham (2007). Risk factors associated with porcine cysticercosis in selected districts of Eastern and Southern provinces of Zambia. Veterinary Parasitology. 143, pp. 59-66.

Silva, C.V. and Costa-Cruz, J.M. (2010). A glance at Taenia saginata infection, diagnosis, vaccine, biological control and treatment. Infect Disord Drug Targets. 10(5), pp. 313-321.

Silverman, P.H. and Griffiths, R.B. (1955). A review of methods of sewage disposal in Great Britain, with special reference to the epizootiology of Cysticercus bovis. Annals of Tropical Medicine \&amp; Parasitology. 49, pp. 436-450.

Smith, J.M.D. (1969). The phisiology and biochemistry of Cestodes. Cambridge University Pres. Cambridge.

Sotelo, J. and Jung, H. (1998). Pharmacokinetic optimisation of the treatment of neurocysticercosis. Clinical pharmacokinetics. 34, pp. 503-515.

Steinmann, P., Utzinger, J., Du, Z.-.W., Jiang, J.-.Y., Chen, J.-.X., Hattendorf, J. et al. (2011). Efficacy of single-dose and triple-dose albendazole and mebendazole against soil-transmitted helminths and Taenia spp.: a randomized controlled trial. PloS one. 6, pp. e25003.

Storey, G.W. (1987). Survival of tapeworm eggs, free and in proglottids, during simulated sewage treatment processes. Water Research. 21, pp. 199-203. 
Storey, G.W. and Phillips, R.A. (1985). The survival of parasite eggs throughout the soil profile. Parasitology. 91(3), pp. 585-590.

Straub, T.M., Pepper, I.L. and Gerba, C.P. (1993). Hazards from pathogenic microorganisms in land-disposed sewage sludge. Reviews of environmental contamination and toxicology. Springer. pp. 55-91.

Tembo, A. and Craig, P.S. (2015). Taenia saginata taeniosis: copro-antigen time-course in a voluntary self-infection. Journal of helminthology. 89, pp. 612-619.

Thomas, H. and Gönnert, R. (1978). [The efficacy of praziquantel against experimental cysticercosis and hydatidosis (author's transl)]. Zeitschrift fur Parasitenkunde (Berlin, Germany). 55, pp. 165-179.

Thomas, L.F. (2015). Landscape Analysis: Control of Taenia solium. World Health Organization.

Thys, S., Mwape, K.E., Lefèvre, P., Dorny, P., Marcotty, T., Phiri, A.M. et al. (2015). Why Latrines Are Not Used: Communities' Perceptions and Practices Regarding Latrines in a Taenia solium Endemic Rural Area in Eastern Zambia. PLOS Neglected Tropical Diseases. 9, pp. e0003570. doi: 10.1371/journal.pntd.0003570.

Toregerson, P.R. (2013). One world health: Socioeconomic burden and parasitic disease control priorities. Veterinary Parasitology. 195(3-4), pp. 223-232.

Torgerson, P.R., Devleesschauwer, B., Praet, N., Speybroeck, N., Willingham, A.Lee, Kasuga, F. et al. (2015). World Health Organization Estimates of the Global and Regional Disease Burden of 11 Foodborne Parasitic Diseases, 2010: A Data Synthesis. PLoS Med. 12, pp. e1001920.

Uygur-Bayramicli, O., Ak, O., Dabak, R., Demirhan, G. and Ozer, S. (2012). Taenia saginata a rare cause of acute cholangitis: a case report. Acta Clinica Belgica. 67(6), pp. 436-437.

Verbyla, M.E., Oakley, S.M., Lizima, L.A., Zhang, J., Iriarte, M., Tejada-Martinez, A.E. et al. (2013). Taenia eggs in a stabilization pond system with poor hydraulics: concern for human cysticercosis?. Water Science and Technology. 68, pp. 2698-2703. doi: 10.2166/wst.2013.556.

Vinnerås, B., Björklund, A. and Jönsson, H. (2003). Thermal composting of faecal matter as treatment and possible disinfection method--laboratory-scale and pilot-scale studies. Bioresource Technology. 88, pp. 47-54.

von Sperling, M., Chernicharo, C., Soares, A.M.E. and Zerbini, A.M. (2002). Coliform and helminth eggs removal in a combined UASB reactor-baffled pond system in Brazil: performance evaluation and mathematical modelling. Water Science and Technology. 45, pp. 237-242.

Vora, S.H., Motghare, D.D., Ferreira, A.M., Kulkarni, M.S. and Vaz, F.S. (2008). Prevalence of human cysticercosis and taeniasis in rural Goa, India. The Journal of communicable diseases. 40, pp. 147-150.

WHO (2015). Landscape analysis: management of neurocysticercosis with an emphasis on low-and middle-income countries.

Wongworapat, K., Keawvichit, R., Putsyanant, P., Khantawa, B., Silprasert, A. and Karnchanawong, S. (2001). Examination of intestinal parasites and enteric bacteria in the wastewater and treated wastewater from the city of Chiang Mai, Thailand. Southeast Asian journal of tropical medicine and public health. 32, pp. 236-239.

Yaya-Beas, R.-.E., Ayala-Limaylla, C., Kujawa-Roeleveld, K., van Lier, J.B. and Zeeman, G. (2015). Helminth Egg Removal Capacity of UASB Reactors under Subtropical Conditions. Water. 7, pp. 2402-2421.

Yousefi, Z., Enayati, A. and Mohammadpoor, R. (2009). Parasitic contamination of wells drinking water in Mazandaran Province. Journal of Environmental Health Science \&amp; Engineering. 6, pp. 241-246.

Zammarchi, L., Strohmeyer, M., Bartalesi, F., Bruno, E., Muñoz, J., Buonfrate, D. et al. (2013). Epidemiology and management of cysticercosis and Taenia solium taeniasis in Europe, systematic review 1990-2011. PloS one. 8, pp. e69537. 